almost incredulous envy in countries where such addiction is still a serious problem. These measures have been wholly salutary, but future legislation concerning the safety of drugs is bound to be more difficult, because no drug is ever entirely safe and its safety must be related to the purpose for which it is to be used. For example, a high degree of toxicity might be tolerated if a drug cured or stayed the progress of an otherwise fatal disease, but no significant toxicity would be permissible in a drug used for a trivial condition or if it was shown to be worthless. This brings up the whole question of efficacy and of relative efficacy; and who is going to dogmatize on this ? Again, who is going to say that the occasional fatal toxic reactions which may result, for instance, from the use of psychotrophic drugs in depressive illnesses are or are not greater than the danger of an increased incidence of suicide if such drugs are forbidden?
Doubtless a committee of experts will advise the appropriate Ministers, and if experts are occasionally wrong they are less often wrong than non-experts. Nevertheless, we interfere with the prescribing doctor's final freedom of decision at our peril in a free democracy. It is easy to set up a sort of pontifical therapeutic Establishment ; but Establishments-Aristotle and Galen, for instance-have not always been in the van of progress.

\section{REFERENCES}

Garai, P. I. (1964). In Drugs in Our Society, edited by P. Talalay, p. 189. Oxford Univ. Press, London.

Hill, A. B. (1960). In Controlled Clinical Trials. Papers delivered at the Conference convened by C.O.I.M.S., p. 7. Blackwell, Oxford.

Smithells, R. W. (1965). Practitioner, 194, 104.

Witts, L. J. (1960). In Controlled Clinical Trials. Papers delivered at the Conference convened by C.O.I.M.S., p. 8. Blackwell, Oxford.

\title{
Systemic Hypertension and Mitral Valve Disease
}

\author{
H. I. OBEYESEKERE, ${ }^{*} \dagger$ M.D., M.R.C.P. ; M. DULAKE,* M.A., M.B., M.R.C.P. ; \\ H. DEMERDASH,* M.D. ; R. HOLLISTER,* M.D.
}

Brit. med. F., 1965, 2, 441-445

There are many conflicting reports concerning the frequency of systemic hypertension in patients suffering from mitral valve disease, and many theories concerning the relation between the two conditions. We have made a further study of the problem from the case records and necropsy reports of patients with mitral stenosis treated at Hammersmith Hospital. An investigation of patients at present suffering from hypertension and mitral stenosis is in hand and will form the subject of a further communication.

The earliest references in the literature to renal involvement in mitral valve disease were those of Bamberger (1857) and Goodhart (1880), who found a high incidence of mitral stenosis associated with granular kidney at necropsy. Pitt (1887), making an extensive study of necropsy material, was very impressed by this frequent association and suggested that in middle-aged patients mitral stenosis was secondary to hypertension and renal disease. Gibson (1909), describing clinical investigations, stated that the blood-pressure in mitral stenosis is "often below the normal, but even more frequently above it." Cowan and Fleming (1912), while recognizing the rheumatic origin of mitral valve disease, suggested that rheumatism was also responsible for the associated renal fibrosis that occurred in these patients. Carey Coombs (1924) attributed the cardiac and renal lesions to scarlet fever. He suggested that the same attack of scarlet fever which set in motion nephritis and led to progressive renal fibrosis and hypertension also initiated progressive fibrosis of the mitral valve.

Boas and Fineberg (1926) found hypertension (systolic pressure over 150 and diastolic over $90 \mathrm{~mm}$. Hg) in $29 \%$ of a series of 135 cases of mitral stenosis of all ages, $50 \%$ being in those over 40 years of age. They suggested that the hypertension and granular kidneys often found at necropsy in these patients was due to renal anoxia from a low cardiac output. Levine and Fulton (1928) studied the blood-pressure of 762 patients with mitral stenosis and found the average pressures of patients over 45 years to be higher than those of normal

\footnotetext{
* Department of Medicine (Clinical Cardiology), Postgraduate Medical School of London and Hammersmith Hospital.

+ Work done during the tenure of a Nuffield Dominion Travelling Fellowship.
}

persons of the same age and frank hypertension to be present in the majority. They suggested that hypertension often proved beneficial by stretching the mitral valves as a result of left ventricular dilatation, and that hypertension by adding to the load on the left ventricle tended to balance the burden on the right ventricle resulting from mitral stenosis. They attributed congestive failure to an imbalance in work of the two sides of the heart.

Then followed a series of reports which denied any association between mitral stenosis and hypertension. Brumm and Smith (1941) found hypertension in only $2 \%$ of these patients with mitral stenosis. Horns (1944) found hypertension in only $10 \%$ of patients under 45 years, and in $30 \%$ of those over 45 years, an incidence no different from that in his controls series. Roseman and Wasserman (1951) gave similar figures in a study of 517 patients, and found no difference between these patients and 2,000 consecutive hospital admissions. Gray (1954) found an incidence of $16.5 \%$ of 200 cases of mitral stenosis not significantly higher than that of 200 controls. He further found that hypertension in mitral stenosis is "essential" and not renal in origin. Wood (1956) found a blood-pressure of 160/100 or over in only $3 \%$ of his series, and stated that hypertension associated with mitral stenosis was almost certainly a matter of chance.

\section{Present Investigation}

The records of 434 patients admitted to Hammersmith Hospital since 1952 suffering from rheumatic mitral valve disease were studied. The diagnosis was made clinically and confirmed in many cases during cardiac surgery or at necropsy. The blood-pressure readings used were the average consistent pressures recorded, and many were basal readings taken during the patients' stay in hospital. Where the patient had been followed for many years the highest consistent recordings were taken. Patients with predominant aortic valve disease were excluded because of the distortion of blood-pressure that is known to occur.

The mean diastolic blood-pressures of patients with mitral valve disease were compared with the diastolic pressures in a 
population sample studied by Hamilton et al. (1954), drawn from the out-patients attending clinics for skin disease, for varicose veins, orthopaedics, and dental treatment.

The diastolic pressure has been regarded as a better guide to true hypertension than the systolic by many authorities (Friedberg, 1956; Wood, 1956). We have therefore graded our patients into four groups according to their diastolic pressure: group 1, under 90 ; group 2, 90-109 ; group 3, 109-129 ; group $4,130 \mathrm{~mm} . \mathrm{Hg}$ and above. For the purpose of this study we regarded patients with a diastolic pressure of $90 \mathrm{~mm}$. $\mathrm{Hg}$ and over as abnormal, as had been the practice of other workers (Friedberg, 1956 ; Perera, 1959 ; Sokolow, 1962). The frequency distribution of patients with diastolic pressures over 90 was compared with that of a cross-section of a population corrected for age. Master et al. (1943) studied the blood-pressure of 14,849 persons over 40 years of age $(5,737$ industrial workers, 2,610 residents of homes for the aged, and 6,502 patients admitted to Mount Sinai General Hospital, New York). They were taken to represent a cross-section of the population in middle and later life.

The effect of increasing age on the cardiac rhythm of patients with mitral valve disease and the effects of the rhythm on the incidence of hypertension (and the effect of hypertension on the rhythm of these patients) were also studied. The necropsy records of 133 patients suffering from mitral valve disease were studied with particular reference to the state of their kidneys. The incidence of renal disease in this group was compared with a control series matched for age and sex irrespective of the cause of death from a consecutive series of necropsies carried out at Hammersmith Hospital. The renal lesions were studied in relation to their blood-pressures and cardiac rhythm in life.

\section{Results}

The age and sex distribution of 434 patients whose records were studied is given in Table $I$. There were 304 females and 130 males, a female:male ratio of $2.3: 1$; and $301(69 \%)$ patients were over 40 years, there being a marked decline in the number of patients after the sixth decade.

TABLE I.-Age and Sex Distribution of 434 Patients with Mitral Valve Disease

\begin{tabular}{l|c|c|c|c|c|c|c|c|c}
\hline \multicolumn{1}{c|}{ Age : } & $0-9$ & $10-19$ & $20-29$ & $30-39$ & $40-49$ & $50-59$ & $60-69$ & $70-79$ & Total \\
\hline Males. & 1 & 4 & 10 & 24 & 41 & 33 & 13 & 4 & 130 \\
Females & 1 & 5 & 23 & 65 & 79 & 82 & 33 & 16 & 304 \\
\hline Total & 2 & 9 & 33 & 89 & 120 & 115 & 46 & 20 & 434 \\
\hline
\end{tabular}

In Table II the mean diastolic blood-pressure of patients with mitral valve disease is compared with the diastolic pressure of a population sample (Hamilton et al., 1954). As the number of patients per five-year age group was small, 10-year age groups were used. The mean diastolic pressures of the patients were higher than those of the population sample.

TABLE II.-Mean Diastolic Blood-pressure of Patients with Mitral Valve Disease Compared with Population Sample (Hamilton et al., 1954)

\begin{tabular}{|c|c|c|c|c|c|}
\hline \multirow[b]{2}{*}{ Age } & & \multicolumn{2}{|c|}{ Males } & \multicolumn{2}{|c|}{ Females } \\
\hline & & $\begin{array}{l}\text { Mitral Valve } \\
\text { Disease }\end{array}$ & $\begin{array}{l}\text { Population } \\
\text { Sample }\end{array}$ & $\begin{array}{c}\text { Mitral Valve } \\
\text { Disease }\end{array}$ & $\begin{array}{l}\text { Population } \\
\text { Sample }\end{array}$ \\
\hline $\begin{array}{l}20-29 \\
30-39 \\
40-49 \\
50-59 \\
60-69 \\
70-79\end{array}$ & $\begin{array}{l}\cdots \\
\cdots \\
\cdots \\
\cdots\end{array}$ & $\begin{array}{r}78.6 \\
86.9 \\
87 \cdot 2 \\
91 \cdot 2 \\
102.0 \\
105.5\end{array}$ & $\begin{array}{l}74 \cdot 0 \\
75 \cdot 9 \\
78 \cdot 3 \\
84 \cdot 2 \\
86 \cdot 6 \\
86 \cdot 3\end{array}$ & $\begin{array}{r}73.4 \\
82.7 \\
88.3 \\
94.0 \\
97 \cdot 0 \\
106.6\end{array}$ & $\begin{array}{l}74 \cdot 5 \\
77 \cdot 0 \\
82 \cdot 1 \\
88 \cdot 2 \\
93 \cdot 1 \\
94 \cdot 4\end{array}$ \\
\hline
\end{tabular}

In Table III the patients are grouped by decade and diastolic blood-pressure. Fifty-two per cent. had a pressure over $90 \mathrm{~mm}$. $\mathrm{Hg}$; of these $10 \%$ were between 110 and $120 \mathrm{~mm}$. $\mathrm{Hg}$, and $2 \%$ were above $130 \mathrm{~mm}$. $\mathrm{Hg}$.

TABLE III.-Diastolic Blood-pressure in Patients with Mitral Valve
Disease

* Complicated by coarctation of the aorta.

In Table IV the patients with a diastolic pressure of 90 or over are grouped together by decade irrespective of sex and compared with the frequency distribution of a general population as determined by Master et al. (1943) (mean for both sexes calculated). Master et al. (1943) have shown that with increasing age there is a gradual rise in the incidence of a diastolic pressure over $90 \mathrm{~mm}$. Hg from the fifth to the eighth decade. Our patients have a much higher incidence of raised pressures and show a very steep rise from the fifth to the sixth decade, a more gradual rise from the sixth to the seventh, and a slight fall in the eighth.

TABLE IV.-Incidence of Raised Diastolic Blood-pressure : Patients with
Mitral Valve Disease Compared with General Population

\begin{tabular}{|c|c|c|c|c|c|}
\hline \multirow{3}{*}{ Age } & & \multicolumn{3}{|c|}{ Mitral Valve Disease } & \multirow{3}{*}{$\begin{array}{c}\begin{array}{c}\text { General } \\
\text { Population* }\end{array} \\
\text { Diastolic B.P. } \\
\text { over } 90 \\
\text { mm. Hg }\end{array}$} \\
\hline & & \multirow{2}{*}{ Total No. } & \multicolumn{2}{|c|}{ Diastolic B.P. over $90 \mathrm{~mm} . \mathrm{Hg}$} & \\
\hline & & & No. & $\%$ & \\
\hline $\begin{array}{l}40-49 \\
50-59 \\
60-69 \\
70-79\end{array}$ & $\begin{array}{l}\ldots \\
\cdots \\
\cdots\end{array}$ & $\begin{array}{r}120 \\
115 \\
46 \\
20\end{array}$ & $\begin{array}{l}58 \\
77 \\
35 \\
13\end{array}$ & $\begin{array}{l}48 \\
67 \\
76 \\
65\end{array}$ & $\begin{array}{l}24 \cdot 6 \% \\
38.4 \% \\
44.8 \% \\
49 \cdot 6 \%\end{array}$ \\
\hline
\end{tabular}

* Figures derived from 14,849 persons over 40 years of age (industrial workers, residents of homes for the aged,
New York) (Master et al., 1943).

Although all the blood-pressures were taken by the auscultatory method, there was a difference in recording the diastolic blood-pressure in the two series. On the recommendation of the American Heart Association, Master et al. (1943), in nearly two-thirds of their readings, took the fifth phase (the complete disappearance of sound) rather than the fourth phase (the definite diminution in intensity of sounds) as the diastolic blood-pressure. Our clinicians, however, as is the custom in Britain, used the fourth phase. Since the blood-pressure reading at that point averages at least $5 \mathrm{~mm}$. higher than the fifth, it seems that had the former method been constantly employed the percentages of hypertension in this series would have been higher. The difference in the incidence of hypertension in the two series is therefore slightly exaggerated.

In Table $\mathrm{V}$ the rhythm of different patients is shown by decade, and illustrates the sharp decline in the incidence of sinus rhythm that occurs from the third to the sixth decade and a corresponding sharp rise in the incidence of atrial fibrillation. Beyond the sixth decade this tendency is somewhat reversed, with an increase in the incidence of patients in sinus rhythm and a corresponding fall in the percentage of atrial fibrillation.

\begin{tabular}{|c|c|c|c|c|c|}
\hline \multirow{2}{*}{ Age } & \multicolumn{2}{|c|}{ Sinus Rhythm } & \multicolumn{2}{|c|}{ Atrial Fibrillation } & \multirow{2}{*}{ Total No. } \\
\hline & No. & $\%$ & No. & $\%$ & \\
\hline $\begin{array}{c}0-9 \\
10-19 \\
20-29 \\
30-39 \\
40-49 \\
50-59 \\
60-69 \\
70-79\end{array}$ & $\begin{array}{r}2 \\
9 \\
23 \\
36 \\
34 \\
14 \\
11 \\
7\end{array}$ & $\begin{array}{r}100 \\
100 \\
70 \\
40 \\
28 \\
12 \\
24 \\
35\end{array}$ & $\begin{array}{r}0 \\
0 \\
10 \\
53 \\
86 \\
101 \\
35 \\
13\end{array}$ & $\begin{array}{r}0 \\
0 \\
30 \\
60 \\
72 \\
88 \\
76 \\
65\end{array}$ & $\begin{array}{r}2 \\
9 \\
33 \\
89 \\
120 \\
115 \\
46 \\
20\end{array}$ \\
\hline
\end{tabular}


Table VI gives the rhythm of patients in the different bloodpressure groups and also compares the incidence of hypertension in patients with atrial fibrillation with those in sinus rhythm$54 \%$ of those with normal pressures, $81.5 \%$ of those with diastolic pressures of 90 to $129 \mathrm{~mm}$. $\mathrm{Hg}$, and all those with a pressure over $130 \mathrm{~mm}$. $\mathrm{Hg}$ were in atrial fibrillation; $61 \%$ of those in atrial fibrillation and $29 \%$ of those in sinus rhythm had hypertension. There was a very significant difference in the incidence of hypertension in patients with atrial fibrillation compared with those in sinus rhythm $\left(\chi^{2}=38.27 ; \mathrm{P}<0.001\right)$.

TABLe VI.-Mitral Series: Cardiac Rhythm and Diastolic Blood-pressure

\begin{tabular}{|c|c|c|c|c|c|}
\hline Diastolic & B.P. & & $\begin{array}{l}\text { Total No. of } \\
\text { Patients }\end{array}$ & Sinus Rhythm & $\begin{array}{c}\text { Atrial } \\
\text { Fibrillation }\end{array}$ \\
\hline $\begin{array}{l}\text { Under } 90 \\
90-109 . \ldots \\
110-129 \\
130 \text { and Over }\end{array}$ & & $\begin{array}{l}\cdots \\
\cdots \\
\cdots\end{array}$ & $\begin{array}{r}211 \\
172 \\
44 \\
7\end{array}$ & $\begin{array}{c}96(46 \%) \\
32(19 \%) \\
8(18 \%) \\
0(0 \%)\end{array}$ & $\begin{array}{c}115(54 \%) \\
140(81 \%) \\
36(82 \%) \\
7(100 \%)\end{array}$ \\
\hline
\end{tabular}
Cardiac rhythm in patients with raised diastolic blood-pressure
298 patients were in atrial fibrillation - $61 \%$ had a diastolic pressure over $90 \mathrm{~mm}$. $\mathrm{Hg}$ 136 patients were in sinus rhythm-29\% had a diastolic-pressure over $90 \mathrm{~mm}$. $\mathrm{Hg}$

\section{Necropsy Studies}

The state of the kidneys in 133 patients with mitral valve disease was analysed. Renal infarction was found in all age groups but Table VII : $69(52 \%)$ had evidence of renal infarction; $13(10 \%)$ had chronic pyelonephritis; $9(7 \%)$ had miscellaneous kidney disease; 6 (4\%) had arteriosclerotic changes, while $36(27 \%)$ had no abnormal renal condition. Table VII also gives the age distribution of the patients at death and shows the effect of age on the renal pathology of patients with mitral valve disease. Renal infarction was found in all age groups but occurred chiefly beyond the third decade. The maximum incidence $(61.1 \%$ ) was in the sixth decade. Cases of chronic pyelonephritis and arteriosclerotic changes were also found in the later decades. Patients with normal kidneys tended to be more frequent in the younger age groups.

TABLE VII.-Renal Lesions in Mitrals Compared with Controls

\begin{tabular}{|c|c|c|c|c|c|c|c|c|}
\hline \multirow{2}{*}{\multicolumn{2}{|c|}{ Age }} & \multirow{2}{*}{$\begin{array}{l}\text { Total } \\
\text { No. }\end{array}$} & \multicolumn{2}{|c|}{$\begin{array}{c}\text { Renal } \\
\text { Infarction }\end{array}$} & \multirow{2}{*}{$\begin{array}{c}\text { Chronic } \\
\text { Pyelo- } \\
\text { nephritis }\end{array}$} & \multirow{2}{*}{$\begin{array}{l}\text { Misc. } \\
\text { Path. }\end{array}$} & \multirow{2}{*}{$\begin{array}{l}\text { Arterio- } \\
\text { sclerosis }\end{array}$} & \multirow{2}{*}{ Normal } \\
\hline & & & No. & $\%$ & & & & \\
\hline $\begin{array}{l}10-19 \\
20-29 \\
30-39 \\
40-49 \\
50-59 \\
60-69 \\
70-79 \\
80-89\end{array}$ & $\begin{array}{l}. \\
\because \\
\because \\
\because \\
\therefore \\
.\end{array}$ & $\begin{array}{r}1 \\
8 \\
21 \\
31 \\
36 \\
24 \\
11 \\
1\end{array}$ & $\begin{array}{r}1 \\
2 \\
10 \\
15 \\
22 \\
13 \\
5 \\
1\end{array}$ & $\begin{array}{l}2 \overline{25} \\
47 \cdot 6 \\
48 \cdot 4 \\
61 \cdot 1 \\
54 \cdot 2 \\
45 \\
-\end{array}$ & $\begin{array}{l}0 \\
0 \\
0 \\
5 \\
3 \\
2 \\
3 \\
0\end{array}$ & $\begin{array}{l}0 \\
1 \\
1 \\
1 \\
4 \\
2 \\
0 \\
0\end{array}$ & $\begin{array}{l}0 \\
0 \\
0 \\
2 \\
0 \\
3 \\
1 \\
0\end{array}$ & $\begin{array}{r}0 \\
5 \\
10 \\
8 \\
7 \\
4 \\
2 \\
0\end{array}$ \\
\hline Total & .. & 133 & 69 & $52 \%$ & $13(10 \%)$ & $9(7 \%)$ & $6(4 \%)$ & $36(27 \%)$ \\
\hline Controls & $\ldots$ & 133 & 6 & $4 \%$ & $16(12 \%)$ & $30(23 \%)$ & $10(7 \%)$ & $71(54 \%)$ \\
\hline
\end{tabular}

Table VII also describes the renal pathology found in the control series of 133 consecutive necropsies carried out at Hammersmith Hospital matched for age and sex with our postmortem material. There was a significant difference in the incidence of renal infarction in patients with mitral valve disease when compared with the controls $\left(\chi^{2}=73.68 ; \mathrm{P}<0.001\right)$.

Table VIII shows the relation between renal pathology and cardiac rhythm, also the very high incidence of atrial fibrillation in patients with renal infarction. Only two patients with renal infarction were in sinus rhythm and both gave a history of subacute bacterial endocarditis. There was a significant difference in the incidence of renal infarction in patients with mitral disease and atrial fibrillation when compared with patients in sinus rhythm $\left(\chi^{2}=42.70 ; \mathrm{P}<0.001\right)$. Threequarters of the patients with chronic pyelonephritis were in sinus rhythm, while in the other three groups about half were in sinus rhythm and the other half in atrial fibrillation.
Table VIII.-Renal Lesions (Post Mortem) and Cardiac Rhythm

\begin{tabular}{|c|c|c|c|c|c|c|}
\hline & & $\begin{array}{c}\text { Renal } \\
\text { Infarction }\end{array}$ & $\begin{array}{c}\text { Chronic } \\
\text { Pyelo- } \\
\text { nephritis }\end{array}$ & Misc. & $\begin{array}{l}\text { Arterio- } \\
\text { sclerosis }\end{array}$ & $\begin{array}{l}\text { Normal } \\
\text { Kidneys }\end{array}$ \\
\hline $\begin{array}{l}\text { No. of patients } \\
\text { Sinus rhythm } \\
\text { Atrial fibrillation } \\
\text { Not known .. }\end{array}$ & $\begin{array}{l}\ldots \\
\because \\
\cdots\end{array}$ & $\begin{array}{l}69 \\
2(3 \%) \\
67(97 \%)\end{array}$ & $\begin{array}{l}13 \\
7(78 \%) \\
2(22 \%) \\
4\end{array}$ & $\begin{array}{l}9 \\
4(45 \%) \\
5(55 \%)\end{array}$ & $\begin{array}{l}6 \\
3(50 \%) \\
3(50 \%)\end{array}$ & $\begin{array}{l}36 \\
20(55 \%) \\
16(45 \%)\end{array}$ \\
\hline
\end{tabular}

Table IX shows the cardiac rhythm in patients who were hypertensive, related to renal infarction at necropsy. Here again there was a very high incidence of atrial fibrillation in patients with renal infarction.

TABLE IX.-Mitral Valve Disease with Raised Diastolic Blood-pressure

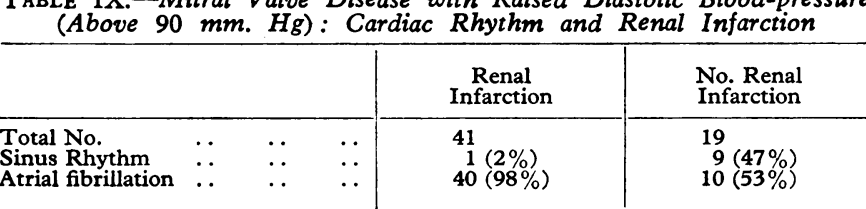

In Table $\mathrm{X}$ is given the blood-pressure found in the five groups of patients sub-divided according to their kidney pathology.

TABLE X.-133 Necropsies in Mitral Valve Disease: Blood-pressure and

\begin{tabular}{|c|c|c|c|c|c|}
\hline \multicolumn{6}{|c|}{ Renal Patnology } \\
\hline $\begin{array}{c}\text { Diastolic B.P. } \\
\text { (mm. Hg) }\end{array}$ & $\begin{array}{c}\text { Renal } \\
\text { Infarction }\end{array}$ & $\begin{array}{l}\text { Chronic } \\
\text { Pyelo- } \\
\text { nephritis }\end{array}$ & Misc. & $\begin{array}{l}\text { Arterio- } \\
\text { sclerosis }\end{array}$ & $\begin{array}{l}\text { Normal } \\
\text { Kidneys }\end{array}$ \\
\hline $\begin{array}{ll}\text { Under } 90 & . \\
90-109 & \ldots \\
110-129 & \ldots \\
130+ & \\
\text { Not known }\end{array}$ & $\begin{array}{r}26 \\
37 \\
3 \\
1 \\
2\end{array}$ & $\begin{array}{l}7 \\
2 \\
1 \\
2 \\
1\end{array}$ & $\begin{array}{l}6 \\
0 \\
2 \\
0 \\
1\end{array}$ & $\begin{array}{l}0 \\
2 \\
3 \\
1 \\
0\end{array}$ & $\begin{array}{r}29 \\
7 \\
0 \\
0 \\
0\end{array}$ \\
\hline Total ... & 69 & 13 & 9 & 6 & 36 \\
\hline
\end{tabular}

Table XI gives the post-mortem renal pathology in those patients with hypertension. This shows that over two-thirds of those with a raised diastolic pressure had evidence of renal infarction at death; $8 \%$ had chronic pyelonephritis; one patient had a renal abscess and one had polyarteritis nodosa, both classified under the miscellaneous group (2\%); $10 \%$ had arteriosclerotic changes in the renal vessels; and $12 \%$ had no abnormal renal pathology.

\section{TABLE XI.-Renal Lesions at Necropsy in Mitral Valve Disease with Raised Diastolic Blood-pressure (Above $90 \mathrm{~mm}$. Hg) Renal infarction.. Chronic pyelonepi. Arteriosclerosis Miscellaneous $\left\{\begin{array}{l}\begin{array}{l}\text { Renal abscess } \\ \text { Polyarteritis }\end{array}\end{array}\right.$. Normal kidneys

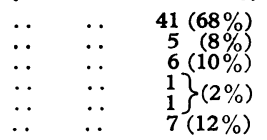

\section{Discussion}

De Graff and Lingg (1935) gave the average age at death of patients suffering from mitral valve disease as 29 for those in normal rhythm and 38 for those in atrial fibrillation. Wood (1956) gave the figure as 40 years. It is therefore not surprising that workers in the past two decades have consistently reported that hypertension in mitral stenosis was a chance finding, for patients invariably died before they reached an age when they might develop hypertension. In the present study $301(61 \%)$ patients were over 40 years.

Our results clearly show that the mean diastolic bloodpressure of patients with mitral valve disease is higher than that of the normal population, and, more important perhaps, that the incidence of hypertension is commoner in these patients than in the general population. Studies by Master et al. (1950), Hamilton et al. (1954), and others have indicated that normally there is a gradual progressive rise in blood-pressure with age, with a slightly higher incidence in females than in males, and 
have presented the frequency distribution of blood-pressure levels at various ages. Patients with mitral valve disease show a different pattern, with an earlier steep rise in incidence of raised diastolic pressure up to the sixth decade, a more gradual rise from the sixth to the seventh, and a slight decline from the seven to the eighth decade. Similarly, the incidence of atrial fibrillation amongst our patients showed a sharp rise up to the sixth decade, and then an abrupt fall from the sixth to the eighth. This relative increase in the proportion of elderly patients in sinus rhythm probably reflects the survival of only those with mild mitral valve disease. There were 115 patients in the sixth, and 46 and 20 respectively in the seventh and eighth decades.

Fig. 1 illustrates the much steeper rise in the incidence of hypertension among patients from the fourth to the sixth decade when compared with the figures of Master et al. (1950) for the general population. It also illustrates a parallel steep rise in the incidence of atrial fibrillation among patients of the same age. Atrial fibrillation was more common in patients with hypertension, and the converse was also true. Of 298 patients who were in atrial fibrillation $61 \%$ were hypertensive, while only $29 \%$ of 136 patients in sinus rhythm were hypertensive. This strongly suggests that the increased incidence of hypertension in patients with mitral valve disease is somehow linked with the increased incidence of atrial fibrillation.

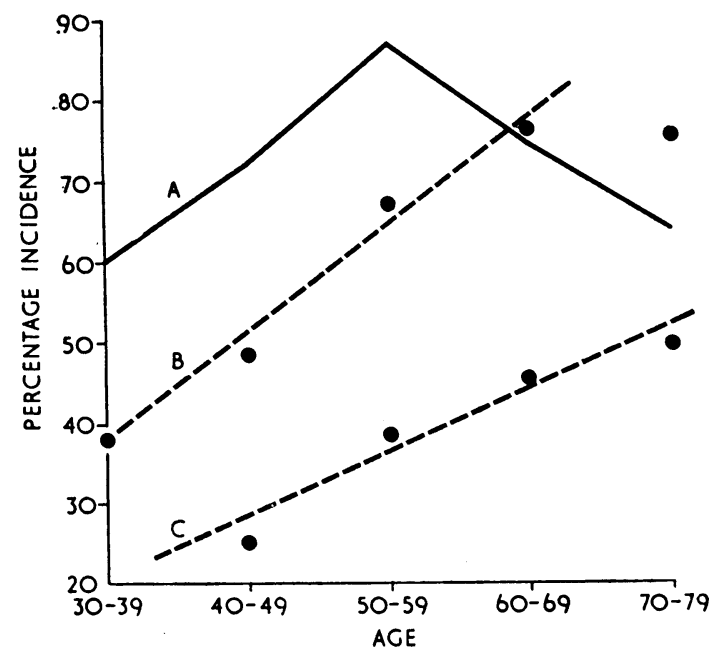

FIG. 1.-A, Incidence of atrial fibrillation in 434 cases of mitral valve disease. $\mathrm{B}$, Incidence of hypertension (diastolic pressure above $90 \mathrm{~mm}$. $\mathrm{Hg}$ ) in 434 cases of mitral valve disease. C, Incidence of hypertension (same criteria) in general population sample (Master et al., 1950).

\section{Necropsy Studies}

The kidneys were abnormal in $73 \%$ of patients with mitral valve disease as compared with $46 \%$ of controls. A highly significant difference was found in the incidence of renal infarction in the two groups. Renal infarction accounted for $72 \%$ of the abnormalities in patients with mitral valve disease and only $10 \%$ of those in the controls. There was no significant difference in the incidence of chronic pyelonephritis and arteriosclerosis in the two groups. The incidence of miscellaneous disorders was higher among controls. This was not surprising, as they included all patients coming to necropsy matched with the mitral patients for age and sex.

The blood-pressure was known in 129 patients with mitral valve disease who came to necropsy. Sixty-one were hypertensive, and renal infarction occurred in 41 (68\%) of them. A study of the rhythm of these patients prior to death shows that $67(97 \%)$ of those with renal infarction were in atrial fibrillation. The other two were patients who gave a history of subacute bacterial endocarditis. Atrial fibrillation occurred in only $22 \%$ of patients with chronic pyelonephritis, while in the other three groups the incidence of sinus rhythm and atrial fibrillation was almost equal. There was an equally striking difference between those who had had hypertension and were found to have renal infarction at necropsy compared with those who had hypertension but no renal infarction. Ninety-eight per cent. of the former and $53 \%$ of the latter group were in atrial fibrillation. In Fig. 2 the effect of increasing age on atrial fibrillation among 434 patients is compared with the effect of age on the incidence of renal infarction found in 133 post-mortem examinations. There is a remarkable similarity in the configuration of the two curves: both rise steeply up to the sixth decade and then fall away. This illustrates the close association between atrial fibrillation, renal infarction, and hypertension in patients with mitral valve disease.

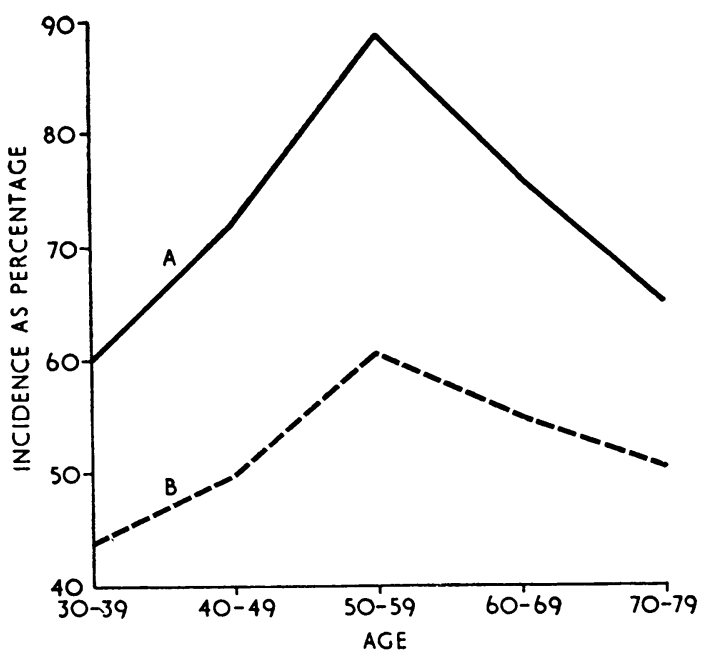

FIG. 2.-A, Incidence of atrial fibrillation in 434 patients. $B$, Incidence of renal infarcts in 133 necropsies on subjects with mitral valve disease.

Goldblatt et al. (1934) demonstrated that hypertension followed partial occlusion of the renal artery and laid the foundation of the renal-pressor theory in man. Prinzmetal et al. (1942) succeeded in obtaining renal perfusate immediately after the death of a patient who in life had chronic rheumatic heart disease (mitral stenosis) and atrial fibrillation, and was observed to become hypertensive following occlusion of his renal arteries. At necropsy both kidneys showed extensive bilateral renal infarction; the obstruction was caused by a large embolus in both renal arteries. The perfusate obtained was demonstrated to have a pressor effect when given to a test animal (a cat). In the same year Fishberg (1942) reported three cases of renal infarction in patients with mitral stenosis, all associated with hypertension.

We have already referred to the steep rise in the incidence of raised diastolic pressures up to the sixth decade in patients with mitral valve disease, which seemed to parallel a similar rise in the incidence of atrial fibrillation in these patients. Our findings also indicate that atrial fibrillation was commoner in patients with mitral valve disease and hypertension than in those with normotension. The incidence of hypertension was significantly higher in patients with atrial fibrillation than in those in sinus rhythm. Now, renal infarction was commoner at necropsy in patients with mitral valve disease than in a control series of necropsies matched for age and sex. Of patients with mitral valve disease who had renal infarction $97 \%$ were in atrial fibrillation; and $98 \%$ of patients with mitral valve disease, raised blood-pressure, and renal infarction were in atrial fibrillation. Two-thirds with a raised diastolic pressure had renal infarction at death. This suggests a close relation between the incidence of atrial fibrillation, hypertension, and renal infarction in these patients.

It is known that in patients with atrial fibrillation renal infarction may follow embolism. We therefore think that patients 
with mitral stenosis may develop hypertension secondary to embolism and renal infarction after atrial fibrillation, to which they are particularly prone in the later years of life. However, of the 69 patients who had renal infarction at necropsy 26 were known to be normotensive in life. A number of these had very recent renal infarction or only a minor degree of renal ischaemia present. Presumably the onset of hypertension depends on a latent interval from the time of embolism and on the amount of ischaemic renal tissue. The extent of scarring has been shown to determine the onset of hypertension in chronic pyelonephritis (Kincaid-Smith, 1955). There were four patients with extensive scarring from renal infarction who were normotensive and in severe congestive cardiac failure prior to death. This same phenomenon was found to occur in living patients with a low cardiac output.

Since the arterial pressure is the resultant of cardiac output and peripheral resistance, patients with a very low cardiac output may not have hypertension in spite of renal ischaemia.

The association of pyelonephritis and hypertension has been recognized since Weiss and Parker (1939) published their paper. They stressed the proliferative endarteritis seen in the diseased kidneys and concluded that the inflammatory reaction which occurs in the kidney substance produces the lesion. This is thought to produce hypertension in response to renal ischaemia by the Goldblatt mechanism. Kincaid-Smith (1955) found that 30 out of 45 patients with chronic pyelonephritis examined at necropsy were hypertensive. The hypertensive patients had severe renal contraction and extensive scarring, whereas the kidneys in the normotensive group were often of normal size with occasional pyelonephritic scars. She showed that occlusive changes often took place in the arcuate arteries within the kidney and that areas in the immediate neighbourhood had undergone an anatomical shrinkage defined as partial infarction. There was evidence of chronic pyelonephritis in 13 patients in the present series: five were hypertensive, seven were normotensive, and in one the blood-pressure was not known.

Now, a diastolic pressure of $90 \mathrm{~mm}$. $\mathrm{Hg}$ may not represent hypertension that is clinically important. Wood mentioned the figure of $160 / 100$, and found only $3 \%$ of his series with pressures above this. But in this study $12 \%$ had a diastolic pressure of $110 \mathrm{~mm}$. $\mathrm{Hg}$ or above and $2 \%$ had a diastolic pressure of 130 and above. These results show that both renal disease and hypertension are common in patients with mitral valve disease.

We do not agree with the more recent suggestion that hypertension in patients with mitral valve disease was a matter of chance. Our results show quite definitely that hypertension is both common and often associated with renal damage. The striking difference between these findings and those of other workers has been explained by the improved prognosis in patients with mitral valve disease to-day due chiefly to cardiac surgery. The improvements in operative technique and the more satisfactory valvotomy usually achieved to-day, compared with that of 10 years ago, should see a further increase in patients reaching the older age groups and thereby a further rise in the incidence of hypertension.

Since most cases of hypertension and renal embolism in mitral valve disease are associated with atrial fibrillation, it is extremely important either to prevent embolism by using anticoagulants in those patients at risk or to remove the risk by atrial appendectomy at surgery or by restoring sinus rhythm. Lown et al. (1962) have shown that by electrical countershock this may be a practical and safe routine. A clear history of embolic phenomena is often singularly lacking in those patients in whom we have demonstrated renal infarction either in life or at necropsy. Further work is in progress to assess the relationship between systemic hypertension and renal infarction in patients with mitral valve disease.

\section{Summary}

A retrospective study was made of 434 case records and 133 necropsy reports in patients with mitral valve disease. These studies have been supported by renal arteriography in selected patients.

Systemic hypertension was commoner than in the population at large when corrected for age. Over half had a diastolic blood-pressure exceeding $90 \mathrm{~mm} . \mathrm{Hg}, 12 \%$ above $110 \mathrm{~mm} . \mathrm{Hg}$, and $2 \%$ over $130 \mathrm{~mm}$. $\mathrm{Hg}$.

Of the cases coming to necropsy $75 \%$ had acquired renal disease, and renal infarction was present in $72 \%$ of these.

There was a close association between atrial fibrillation, renal infarction, and systemic hypertension, all three anomalies showing a parallel increase with age. By the sixth decade $88 \%$ of all the patients had atrial fibrillation. Of the 36 necropsies in the same decade $22(61 \%)$ showed renal infarction.

The results indicate that systemic hypertension often occurs in cases of mitral valve disease and is related to renal embolism and infarction resulting from atrial fibrillation.

The prognostic implications of persistent atrial fibrillation in mitral valve disease and the place of reversion to sinus rhythm are discussed in the light of modern surgical and medical treatment.

We are grateful for assistance given in the preparation of this paper by Professor John F. Goodwin, who suggested the investigation. Professor I. D. P. Wootton kindly advised us on the statistical analysis, and Professor C. V. Harrison on the pathological aspects.

\section{REFERENCES}

Bamberger, H. (1857). Virchows Arch. Path. Anat., 11, 12. Quoted by Boas and Fineberg (1926).

Boas, E. P., and Fineberg, M. H. (1926). Amer. F. med. Sci., 172, 648. Brumm, H. J., and Smith, H. L. (1941). Minn. Med., 24, 664.

Coombs, Carey F. (1924). Rheumatic Heart Disease, p. 29. Wright, Bristol.

Cowan, J., and Fleming, G. B. (1912). Quart. F. Med., 5, 309.

DeGraff, A. C., and Lingg, C. (1935). Amer. Heart Ұ̈., 10, 630.

Fishberg, A. M. (1942). F. Amer. med. Ass., 119, 551.

Friedberg, C. K. (1956). Diseases of the Heart, 2 nd ed. Saunders, Philadelphia.

Gibson, G. A. (1909). Allbutt's System of Medicine, Vol. 6, p. 338. MacMillan, London.

Goldblatt, H., Lynch, J., Hanzal, R. F., and Summerville, W. W. (1934). 7. exp. Med., 59, 347 .

Goodhart, J. F. (1880). Lancet, 1, 479.

Gray, I. R. (1954). Brit. Heart f., 16, 165.

Hamilton, M., Pickering, G. W., Roberts, J. A. F., and Sowry, G. S. C. (1954). Ćlin. Sci., 13, 273.

Horns, H. L. (1944). Amer. Heart f., 28, 435.

Kincaid-Smith, P. (1955). Lancet, 2, 1263.

Levine, S. A., and Fulton, M. N. (1928). Amer. 7. med. Sci., 176, 465 Lown, B., Amarasingham, R., and Neuman, J. (1962). f. Amer. med. Ass., $182,548$.

Master, A. M., Dublin, L. I., and Marks, H. H. (1950). Ibid., 143, 1464

Marks, H. H., and Dack, S. (1943). Ibid., 121, 1251.

Perera, G. A. (1959). Ann. intern. Med., 51, 537

Prinzmetal, M., Hiatt, N., and Tragerman, L. J. (1942). F. Amer. med. Ass., 118, 44.

Pitt, G. N. (1887). Brit. med. F., 2, 118.

Roseman, M. D., and Wasserman, E. (1951). New Engl. F. Med., 245, 450.

Sokolow, M. (1962). Proc. med. Sect. Amer. Life Convention, 50, 19.

Weiss, S., and Parker, F., jun. (1939). Medicine (Baltimore), 18, 221.

Wood, P. H. (1956). Diseases of the Heart and Circulation, 2nd ed. Eyre and Spottiswoode, London. 